\title{
En tierra de ciegos cantores: Granada en la poesía hispánica
}

\author{
Efrén ORTIZ DOMÍNGUEZ \\ Instituto de Investigaciones Lingüístico-Literarias \\ Universidad Veracruzana (México) \\ efortiz@uv.mx
}

Recibido: 02/08/2012

Modificado: $8 / 11 / 2012$

Aceptado: $16 / 11 / 2011$

\section{Resumen}

¿Cuántas maneras posibles existen para describir poéticamente una ciudad? El texto explora imágenes literarias de la ciudad de Granada contenidas en los poemas de Francisco A. de Icaza, Francisco de Villaespesa, Juan Ramón Jiménez, Rafael Alberti y Federico García Lorca, para poner de relieve no sólo la configuración del ambiente arábigo de esa ciudad andaluza sino también para iniciar un inventario de imágenes topológicas. Con ello, se desea poner de relieve la trayectoria histórica, progresiva, de los estereotipos culturales y literarios con los cuales esta ciudad española se identifica.

Palabras clave: ciudad, ciudad literaria, Granada, imagen, poesía.

Title: Land of blind singers: Granada in Hispanic poetry

\section{Abstract}

How many ways are there to poetically describe a city? The text explores literary images of Granada (Spain) in the poems of Francisco A. Icaza, Francisco Villaespesa, Juan Ramón Jiménez, Rafael Alberti and Federico García Lorca to highlight not only the Arabic atmosphere of this Andalusian city settings, but also to start an inventory of topological images. This is wished to highlight the historic, progressive, path of literary and cultural stereotypes with which this Spanish city is identified

Keywords: city, literary city, Granada, picture, poetry.

\section{Índice}

1. Introducción: Granada en la poesía hispánica

2. Francisco A. de Icaza: Granada, "libro de gloria musulmana"

3. Francisco de Villaespesa: Granada, "la de fuentes que desgranan hilos de perla"

4. Juan Ramón Jiménez: Granada, "alta ciudad de cristales vivos"

5. Federico García Lorca: Granada, "ciudad melancólica del ciprés y del agua"

6. Rafael Alberti, el poeta que nunca vio Granada

7. Luis Rosales: Granada, "Ciudad de la Buena Muerte"

8. Conclusiones 


\section{Introducción: Granada en la poesía hispánica}

Las ciudades constituyen un objeto de estudio multiforme y rico en perspectivas. Uno puede abordarlas en su trayectoria histórica o urbanística; desde la perspectiva del peatón o de los diversos grupos sociales que en ella cohabitan; como espacio de coexistencia o como lugar de encuentro de prácticas en conflicto; en fin, como ciudades reales o como objeto de fabulación. Me interesa esta última perspectiva, porque si bien hay ciudades ubicadas exclusivamente en la ficción, como por ejemplo Macondo, Comala o Santa María, las hay, sin embargo, de una especial índole, aquellas que poseen un correlato en la vida, o bien, como caso límite, aquellas que sirven como motivo de inspiración y cuyas características las convierten en motivo literario más o menos universal. Babilonia la grande, Roma la eterna, Estambul, la puerta entre dos mundos o, de manera mucho más próxima, Lima la horrible, o la maravillosa Buenos Aires.

Más allá de su existencia real en el planisferio, de sus intersecciones entre el mundo arábigo y el europeo, luego de su inserción en el mundo literario, Granada adquiere nuevos y portentosos sentidos que exceden la descripción enciclopédica. Su profusa presencia en novelas, cuentos, poemas, ensayos o crónicas hace de ella un objeto de estudio peculiar que nos revela no sólo los rostros habitualmente estudiados en una sociedad por la sociología (ciudad vivida o ciudad deseada), el urbanismo (ciudad real, ciudad imaginada) o la antropología cultural (la ciudad y los imaginarios de los grupos sociales que la integran), sino que a todo ese vasto complejo de sentido se añade el plus desbordante del universo simbólico, histórico y cultural que aproxima a las ciudades reales con las de índole imaginaria. Una mirada a vuelo de pájaro nos permite avizorar su presencia en los textos de Washington Irving, José Zorrilla, Amin Maalouf o Antonio Gala. Todo ello convierte a esa ciudad del sur de Andalucía en espacio de entrecruce de dos culturas, dos identidades históricas, étnicas y culturales diferentes. La lectura de tales textos contribuye a la percepción de la ciudad como espacio de conexión cultural donde es factible hallar de manera simultánea embrujo, magia, fantasía, leyenda e historia. A ello contribuye, sin duda, la contextura histórica, arquitectónica, urbanística que le confiere una identidad singular.

Procuro detenerme en una perspectiva que me permita obviar la manera en que esta ciudad, en el orden de lo real, es cantada por cuatro poetas que la convierten en motivo de exaltación. Me refiero a un par de poetas modernistas: Francisco de Asís de Icaza y Francisco de Villaespesa; mexicano de origen el primero, arraigado por múltiples motivos sentimentales a la ciudad; andaluz el segundo, asentado largos años en América merced a su actividad como autor dramático; autores de sendos libros de títulos cuasi-homónimos, La canción del camino y Canciones del camino (ambos aparecidos en 
Madrid en 1906), que instauran una poética inspirada en motivos, tipos y modelos retóricos de la tradición andaluza, y quienes dedican varios poemas (el segundo incluso un libro completo) a esa ciudad. Ellos, a la vez, constituyen un modelo para la siguiente generación poética española del siglo XX, mejor conocida y estudiada: Rafael Alberti, Juan Ramón Jiménez, Luis Rosales y Federico García Lorca, este último, el mejor y más reconocido autor de una estética hispanoarábiga (en otras palabras, andaluza), que convierte a Granada en ciudad eje para un conjunto de motivos poéticos que devendrán tópico (el de los ciegos cantores gitanos que interpretan coplas), los cuales resultan de la confluencia de la obra de sus predecesores, aquellos otros poetas arriba citados (vid., entre otros, Gallego Morell 1967; Hidalgo 1993; Wojcik 2010).

Me interesa evocar la figura de los ciegos cantores que se extasían ante las maravillas arquitectónicas de la ciudad y que describen sus rasgos característicos. Por ello, se trata de motivos que atañen exclusivamente a esa ciudad y no a otras, también relevantes, como Sevilla y Toledo, que los árabes construyeron en la Península Ibérica. En suma, es del embrujo granadino, así como de las maneras múltiples para representarla poéticamente, de lo que quisiera hablar aquí.

\section{Francisco A. de Icaza: Granada, "libro de gloria musulmana"}

"El mexicano de España y el español de México"; así ha llamado José Emilio Pacheco en su discurso de recepción del Premio Cervantes 2009 (2010: 1) a Francisco A. de Icaza (1863-1925), diplomático que, a muy corta edad, deja nuestro (su) país para permanecer de por vida en Europa; es, por ende, un migrante que refunda patria y que escribe cantos de elogio a su segundo suelo. La compenetración de Icaza en el mundo intelectual y artístico de la Península Ibérica hace de él, a pocos años, un genuino representante de la generación poética finisecular, modernista y que, a la par de Juan Ramón Jiménez y Francisco de Villaespesa, será reconocido como maestro por las jóvenes generaciones vanguardistas. Su hispanismo, evidente en el modo de pronunciar el español a la andaluza, le lleva a escribir un conjunto de poemas que toman a Granada como motivo y locus poético. A Icaza le unen lazos muy estrechos con la ciudad: no sólo aquellos de consanguinidad, por haber contraído nupcias con Beatriz de León y Loynaz, sobrina de los Marqueses de Esquilache y oriunda de aquel lugar, sino aquellos otros gestados al calor de la admiración profunda del esteta que glorifica a la ciudad a través de una copla memorable, hoy adosada a los muros del Generalife: 
Dale limosna, mujer

Que no hay en la vida nada

Como la pena de ser

Ciego en Granada.

Que es una copla de tipo andaluz, donde la admiración hiperbólica se construye -curiosa paradoja- a través de la elipsis, de lo no dicho, de lo ausente o de la carencia. No obstante, preceden a esta genial copla de La canción del camino imágenes moriscas de un acendrado tono modernista en sus dos primeros libros: Efímeras y Lejanías (Madrid, 1892 y 1899). Así, en "Pórtico" (1889), interroga a la amada:

\author{
¿Soñaste con las bóvedas de encaje, \\ Y de la luna al pálido vislumbre \\ Con los bosques de columnas y follaje \\ De calado arabesco por techumbre? \\ ¿Al lado de la fuente que murmura \\ Junto a los solitarios alhaníes \\ Arrastrando su blanca vestidura \\ Miraste abencerrajes y zegríes? \\ Y el viento, perfumado de azahares, \\ Trajo el dulce cantar hasta tu oído \\ De un ave que en la torre de Comares \\ Hizo en un verso del Korán su nido? (Icaza 1980: 132)
}

Por su parte, "La leyenda del beso" (1890), citada profusamente en diccionarios y enciclopedias como un motivo local ligado a la tradición romántica, da lugar a un equívoco, puesto que el poema no habla de pareja o leyenda alguna del pasado, sino que en realidad es un pretexto literario para exaltar, a la par de la pasión presente del poeta, la gloriosa tradición de la ciudad; en otras palabras, sirve para evocar el pasado e inscribir en él, como un hecho intemporal, el romance entre el poeta Icaza y su Beatriz:

Tú sabes que esa rica filigrana

Que los muros decora y festonea

No es vano alarde de riqueza vana

Que es un libro de gloria musulmana

En el que cada trazo es una idea.

Y oirás por las caladas celosías, Cuando mi intento cariñosa ayudes, Kasidas amorosas de otros días, En que cantó Jarhib sus alegrías Al rítmico compás de los laúdes. (Icaza 1980: 151-152)

Otros poemas se detienen en los motivos moriscos clásicos: el huerto interior, la torre, la callejuela estrecha, la mirada femenina 
que se adivina detrás del muro, rasgos de indudable raigambre romántica que enlazan los poemas de Icaza con aquellos otros, aún más famosos, del Don Juan de José Zorrilla. Pero entre la obra de Icaza, son quizás mejor recordadas por su contemporaneidad y gracia las breves composiciones dedicadas al flamenco, la típica danza andaluza, en La canción del camino (Madrid, 1906), libro donde es manifiesto el vuelco poético de nuestro poeta hacia una expresión típicamente hispánica. Así, en "Las flores de tu mantón" vemos:

De la danza en el revuelo

Las flores de tu mantón

Se te enredan en el pelo,

Una tus mejillas toca

Y otra se queda en tu boca

En un clavel reventón. (Icaza 1980: 223)

Icaza no sólo acude a los motivos; la expresión misma está arraigada en las formas de habla, el tono y la viveza de la copla popular del sur de España, lo que le convierte en un claro antecedente de los poetas españoles de la Generación del 27.

\section{Francisco de Villaespesa: Granada, "la de fuentes que desgranan hilos de perla"}

Compañero de tertulias de Icaza por los cafés madrileños, como el Levante o el Fornos, donde ambos tuvieran oportunidad de alternar con Rubén Darío y Julián del Casal, entre otros grandes poetas hispanoamericanos, y con los Machado y Marquina, entre los de origen hispano; de él dijo Juan Ramón Jiménez que era "el cruzado, el púgil del Modernismo en España". El destino de Francisco de Villaespesa ofrece una curiosa antítesis respecto del poeta hispanomexicano: su gran éxito como autor teatral en España le hizo embarcarse como empresario hacia América del Sur, donde permaneció largos años, especialmente en Venezuela, Argentina y Brasil, lugar donde le alcanzó la muerte.

Siendo el Modernismo una corriente que abreva en lo exótico y que recupera temas y motivos de la literatura romántica, no es de extrañar que la presencia de una ciudad como Granada se convierta en eje para una mayor cantidad de composiciones. Lo abona el hecho de haber contado, en el periodo morisco, con una tradición poética propia, que privilegia los temas amorosos de la cual los poetas de origen andaluz se conciben como herederos. Tal es el motivo que impulsa a Francisco de Villaespesa (1877-1936) a tocar el tema en reiteradas ocasiones, incluso, a dedicar un poemario completo a la ciudad, El encanto de la Alhambra, libro constituido por dos secciones: "El encanto de la Alhambra", serie de veintiséis sonetos de carácter esencialmente descriptivo, y "Los nocturnos del Generalife", 
constituidos por setenta y cuatro poemas que incluyen a la par evocaciones de ambiente, nostalgias, retratos femeninos y nocturnos, en el sentido estricto de composiciones nostálgicas dedicadas a la noche. Es, por ello, quizás una monografía literaria cuyo epicentro es la ciudad, sus diversos ambientes, sus personajes típicos, sus motivos y las diversas sensaciones y añoranzas que produce en el poeta. Versos como "La Gran Vía" trazan una estampa sencilla pero señorial:

iGranada no ha sufrido transformación alguna!... La misma luz de seda, la misma paz ambiente;

El Darro se desliza voluptuosamente

Arrullando los cármenes con su vaivén de cuna...

iPaseo de los Tristes!... ¿Recuerdas?... Floreciente

De ensueños, aún suspira su tristeza moruna

En los hilos de perlas que desgrana la fuente

Que evoca una pupila lagrimeando luna. (Villaespesa 1932: 15)

Pero también una serie de estampas visuales, como "La torre de los picos", donde hace convivir la arquitectura del pasado con las nostalgias del presente inmediato, con breves paréntesis en que una y otra época se sobreponen:

iRegia torre! La hiedra lambrequines desata

Por tus nobles almenas... Sobre tu roja veste

Arrojan las estrellas un resplandor celeste

Y la luna el hechizo de su alquicel de plata!...

¿Quién enciende la lámpara que resplandece a veces

Bajo las duras cejas de esos dos ajimeces?...

¿Será la sombra blanca de una princesa ciega,

Que tan fiel en la muerte como lo fue en la vida,

En espera de ese sueño que nunca llega,

Deja todas las noches su lámpara encendida? (Villaespesa 1932: 7576)

Las fuentes de Granada, además de las torres, irrumpen una y otra vez en sus poemas. El Darro y el Genil, los ríos que alimentan los huertos, dotan de voz a esos manantiales, impetuosos los unos, sigilosos los otros, borboteantes los más, a manera de suspiro: el agua es al propio tiempo la sangre y las lágrimas de la ciudad de Granada:

Las fuentes de Granada

¿Habéis sentido

En las noches de estrellas perfumada,

Algo más doloroso que su triste gemido?

$[\ldots]$ 
Algunas se despeñan con ecos de torrentes Y entre las alamedas descienden rumorosas Arrastrando en el vivo fulgor de su corriente En féretros de espumas, cadáveres de rosas.

Otra, por las paredes resbala, lentamente Y entre las verdes hiedras lagrimear se siente; Como si poco a poco, por una estrecha herida, Se fuese desangrando hasta quedar sin vida.

Las hay ciegas, y en ellas

Llora toda la móvil plata de las estrellas.

Hay en el aire tanta humedad, que da frío

La noche un fresco aroma acuático deslíe. (Villaespesa 1917: 24-25)

\section{Juan Ramón Jiménez: Granada, "alta ciudad de cristales vivos"}

Otro de los asiduos a las tertulias del café Fornos es Juan Ramón Jiménez (1881-1958), el poeta del crepúsculo, de los recién casados y de la vida sencilla. En el marco de una producción estética tan vasta, cabe no obstante un paréntesis de nostalgia que se abre en los últimos y más difíciles años del poeta, durante la estancia que, con el pretexto de una agregaduría cultural, encubrió el auténtico exilio que le llevó, con su amada Zenobia, a los Estados Unidos. Con ese amoroso recuerdo, crea un conjunto de estampas de entre las cuales sobresalen los dos libros finales del volumen, escritos en prosa poética, dedicados específicamente a Sevilla y Granada. Este último, está dividido en cuatro secciones: "A Granada", "Granada misma", "Otros olvidos de Granada" y "De Granada". Dice en la segunda sección:

Parece, primero, desde el arriba de contemplativos esfumados a la medialuna, un barrio inmenso de Granada del que aun quedasen, en la quieta agua azul verde, halos vagos, suaves timbres, ascensiones fatuas, temblores encendidos, lentas voces de acostumbrados al fondo. Pasan sombras como peces verticales, entran y salen por su dominio de huecos de encanto... Luego parece que el barrio ingrave está suspenso del cielo alto con colgantes hilados de estrellas. (Jiménez 1994: 235)

Esta imagen celeste, que habremos de hallar también en escritores como Luis Rosales, contrasta vivamente con la de una ciudad vetusta, próxima a la muerte. Las imágenes vanguardistas de Juan Ramón nos entregan una imagen desconcertante de la ciudad:

En Granada, tal casa del abandono, el desahucio, la ruina, toma un gris insólito e indescriptible. Más que casa olvidada de semivivos parece casa semivivita de posmuertos, con complicadas calidades de 
nicho tolerado por la vecindad y tributario normal del municipio. Y los entes de despido que la viven o la mueren (para algo, esto no tiene duda) decoran su silencio extravagante con incompatibles vestuarios de ceniza.

Gatos desteñidos, disecados espectros de gatos con comidos lunares en la cabeza, en el lomo, en el rabo; con ojos revueltos de cristal de color, saltan dentro, fuera, por ventanas desmarcadas, picosas del cristal de lo sucesivo; y van y vienen a raros menesteres por verdes antros vacíos, escalerillas de tenguerengue, cimbrados techos, como pajes correveidiles de imposibilidad del reino de lo inadecuado. (Jiménez 1994: 237-238)

A la desoladora estampa de abandono, de reliquia intocable, propia de las ciudades con una tradición arquitectónica propia, se une no obstante la remembranza del agua, que hemos hallado en Villaespesa, amigo del poeta de Moguer. Juan Ramón se extasía también ante los rumores de fuentes, que parecen susurrar en una lengua propia:

El agua me envolvía con rumores de color y frescor sumos, cerca y lejos, desde todos los cauces, todos los chorros y todos los manantiales. Bajaba sin fin el agua junto a mi oído que recogía puesto a ella, hasta el más fino susurro, con una calidad contajiada [sic] de exquisito instrumento maravilloso de armonía; mejor era, perdido en sí, no ya instrumento, música de agua, música hecha agua sucesiva, interminable. Y aquella música del agua la oía yo más cada vez y menos al mismo tiempo; menos porque ya no era externa, sino íntima, mía; el agua era mi sangre, mi vida, y yo oía la música de mi vida y mi sangre, en el agua que corría. Por el agua yo me comunicaba con el interior del mundo. Se oía más finamente cada vez el agua granadí. A medida que el aire oscurecía y a medida que el agua sonaba, y me afinaba más, más, sonando y resonando, el alma hasta hacerme no oír, decir siendo lo que ella sin duda era o decía. (Jiménez 1994: 239)

\section{Federico García Lorca: Granada, "ciudad melancólica del ciprés y del agua"}

Documentada está, también, la proximidad entre Icaza y ese gran cantor de la Alhambra, de los jinetes y los toreros granadinos, que es Federico García Lorca (1898-1936). La correspondencia (Maurer y Anderson 1997) muestra el respeto que inspiraba al granadino un esteta, historiador del arte y filólogo como Icaza, gran enamorado de su ciudad. De él, consigna su inminente visita y pide a Paquito, su hermano menor, recibir al anciano poeta, con ocasión de alguna conferencia en aquella ciudad -en una carta de noviembre de 1924 (Maurer y Anderson 1997: 255). Del otro costado, Icaza siente simpatía por aquel joven estudiante en Madrid, al ver en sus poemas todos aquellos motivos andaluces que su obra, a la par de la de 
Villaespesa, habían fungido como sendero para una joven generación que proyectaba nuevos derroteros para la poesía española (carta del 13 de mayo de 1923; Maurer y Anderson 1997: 183). Escasamente estudiada, esta influencia de Icaza y Villaespesa se derrama por igual sobre los Machado, Juan Ramón, García Lorca, Alberti y Miguel Hernández, entre otros.

Tres son los poemarios más citados de este poeta nacido en la demarcación granadina y que contienen motivos, alusiones o descripciones del tipo aquí mencionado: Poema del cante jondo (1921), Romancero gitano (1928) y Diván del Tamarit (1936), entre otros. Pero en ese marco de exaltación de la ciudad y su cultura, tan definitoria del sur de la península, quisiera resaltar un poema escasamente estudiado pero que posee, en nuestro contexto, un lugar especial. Se trata de "Granada (Elegía humilde)", primer poema que publicara el escritor en el periódico andaluz Renovación, el 25 de junio de 1919, no exhumado hasta ahora y no incorporado, por tanto, a sus Obras Completas (Gallego Morell 1967: 487). Allí pueden inscribirse una buena cantidad de datos que muestran las influencias que su estética recibe de la tradición, pero también el viraje hacia una manera innovadora de cantar la ciudad. En principio, el foco de atención del poeta desciende gradualmente:

Tu elegía, Granada, la dicen las estrellas

Que horadan desde el cielo tu negro corazón.

La dice el horizonte perdido de tu vega,

La repite solemne la yedra que se entrega

A la muda caricia del viejo torreón. (García Lorca apud Gallego Morel 1967: 491)

Luego, ese canto celeste se traduce en silencios rotos, en aromas, en los murmullos del agua que cantara Villaespesa; con gran audacia, no obstante, la liquidez, símbolo de vitalidad, se convierte en su contrario, el polvo, a manera de alusión a ese otro gran poeta del sur, el cordobés Luis de Góngora:

Tu elegía, Granada, es silencio herrumbroso, Un silencio ya muerto a fuerza de soñar.

Al quebrarse el encanto, tus venas desangraron

El aroma inmortal que los ríos llevaron

En burbujas de llanto hacia el sonoro mar.

El sonido del agua es como un polvo viejo

Que cubre tus almenas, tus bosques, tus jardines, Agua muerta que es sangre de tus torres heridas, Agua que es toda el alma de mil nieblas fundidas Que convierte a las piedras en lirios y jazmines. 
Hoy, Granada, te elevas ya muerta para siempre

En túmulo de nieve y mortaja de sol,

Esqueleto gigante de sultana gloriosa

Devorado por bosques de laureles y rosas

Ante quien vela y llora el poeta español. (García Lorca apud Gallego Morel 1967: 491)

La imagen es, en este sentido, el reverso de sí misma: se yergue frente a la descripción viva y líquida de la tradición, frente a la idea del vetusto esplendor. Eco o rememoración del soneto de Góngora aquí evocado, se ven tan sólo polvo, sombras, cenizas, sangre, túmulo y mortaja, cual si se tratara de una premonición. Luego, el poeta hace de la ciudad su alocutario y se dirige a ella de manera directa, para evocar el pasado grandioso, para vivir la añoranza del illo tempore:

¿Qué se fue de tus muros para siempre, Granada?

Fue el perfume potente de tu raza encantada

Que dejando raudales de bruma te dejó.

$¿ O$ acaso tu tristeza es tristeza nativa

$Y$ desde que naciste aún sigues pensativa

Enredando tus torres al tiempo que pasó? (García Lorca apud Gallego

Morel 1967: 491)

El poeta, finalmente, subraya la amenaza que parece cernirse sobre la ciudad, su gente y su tradición, además de poner de relieve la compenetración existente entre ambos. Y pareciera que los dos últimos versos anunciaran el trágico fin de su autor:

Hoy, ciudad melancólica del ciprés y del agua,

En tus yedras añosas se detenga mi voz.

iHunde tus torreones! Hunde tu Alhambra vieja

Que ya marchita y rota sobre el monte se queja,

Queriendo deshojarse como marmórea flor.

Invaden con la sombra maciza tus ambientes.

iOlvidan a la raza viril que te formó!

Y hoy que el hombre profana tu sepulcral encanto,

Quiero que entre tus ruinas se adormezca mi canto

Como un pájaro herido por astral cazador. (García Lorca apud Gallego Morel 1967: 492)

He subrayado la importancia de esta composición no sólo por el hecho de que está dedicada de manera íntegra a la ciudad, sino porque el tono, el contenido y los motivos que ella utiliza son radicalmente distintos de aquellos con los que tradicionalmente identificamos a García Lorca: aquí no hallamos solamente gitanos, cantores ciegos, toreros o andaluzas, es decir, la ciudad no es el 
motivo estereotipado de corte regionalista, ni el bosquejo de una topografía y una arquitectura posible de fincar en un periodo histórico, sino más bien la oportunidad para hablar acerca de un momento de crisis histórica, del cual la ciudad funge como escenario y emblema.

\section{Rafael Alberti, el poeta que nunca vio Granada}

De las ciudades puede hablarse de manera directa, si el texto pone énfasis en la descripción (como en el caso de las fuentes de Villaespesa); puede dar ocasión a rememorar el pasado, histórico o personal (como en la nostálgica visión de García Lorca); puede emplearse como emblema o convertirse en motivo folclórico (Icaza). De la ciudad también puede hablarse de manera alusiva o elusiva, como en la "Copla del ciego" de Icaza. ¿Podrá acaso también explorarse la imagen de una ciudad por la vía de la negación? ¿Es posible dar por sentado el valor, la tradición, la arquitectura o el carácter de la gente que la puebla, sin conocerla? Tal caso es posible a través de dos vías: cuando el escritor invoca su presencia a través de imágenes tradicionales previamente configuradas, e invoca de la ciudad no su imagen real, que le es desconocida, sino lo que de ella se dice o se presupone, lo que equivaldría a una cita. $O$ bien, hablar de ella a través de imágenes o tópicos que el lector reconoce como inherentes específicamente a esa, y no a otra ciudad. Ambos casos, no obstante, presuponen una tradición, un canon. En el primer caso, Rafael Alberti nos proporciona, en su "Balada del que nunca fue a Granada" (poema musicalizado por Paco Ibañez), un sentido homenaje hacia el cantor por antonomasia de la ciudad, de manera que pudiera subtitularse como "Llanto por la muerte de Federico García Lorca".

Qué lejos por mares, campos y montañas!

Ya otros soles miran mi cabeza cana.

Nunca fui a Granada.

Mi cabeza cana, los años perdidos.

Quiero hallar los viejos, borrados caminos.

Nunca vi Granada.

Hay sangre caída del mejor hermano.

Sangre por los mirtos y aguas de los patios.

Nunca fui a Granada.

Del mejor amigo, por los arrayanes.

Sangre por el Darro, por el Genil sangre.

Nunca vi Granada.

Si altas son las torres, el valor es alto.

Venid por montañas, por mares y campos.

Entraré en Granada. (Alberti 1972: 1093) 
La naturaleza de la cita literaria puede adivinarse detrás de las imágenes y motivos que este poema invoca: el deseo de no ver, de ignorar la sangre caída que es, simultáneamente, la sangre de Ignacio Sánchez Mejía y la de su cantor, los mirtos y arrayanes y las torres altas, ejemplo de cita literaria, más que descripción, porque las enuncia alguien que dice desconocer la ciudad.

\section{Luis Rosales: Granada, "Ciudad de la Buena Muerte"}

El mismo tópico, que mezcla el deseo de morir y la evocación indirecta del amigo muerto, reaparecerá en otro gran poeta andaluz, Luis Rosales (1910-1992), de cuya casa Federico partió con destino a la muerte. Sus "Soleares", dedicadas específicamente a su ciudad de origen, poseen la impronta indeleble de una nostalgia que, no obstante, posee tonos coloridos y sensaciones apacibles.

Si tú quieres

Iré a morir en tus brazos

Ciudad de la Buena Muerte

iQué bien te sienta el otoño

Con tu tristeza dorada

Y el agua buscando novio!

Ya sin sol, casi vacía

Tu muerte se va quedando

Dormida. (Rosales 1982: 383)

En ese marco, las finas descripciones imprimen al paisaje no sólo toques de sensualidad, sino que le añaden tintes de prosopeya:

Tan sola, siempre tan sola

Y la nieve de la sierra

Te está vistiendo de novia! (Rosales 1982: 384)

Por último, veamos un caso de alusión. Se trata de aquellos poemas que, de manera análoga con las anteriores, no enuncian de manera directa sus vínculos con una ciudad de manera específica. No vemos el nombre "Granada" en el título o en las líneas versales; no obstante, los lectores hallan esos vínculos, sea a partir de un canon implícito o de imágenes poéticas que sólo pueden asociar con su correlato real los oriundos del lugar. Hechos legendarios, personajes del lugar, antiguos nombres de calles o barrios, detalles que a veces resultan difíciles de identificar para el lector no nativo. Al respecto, recientemente se ha presentado un libro guía en video de la Alhambra que contiene poemas de Rosales y dibujos de García Lorca (Efe 2011). El crepúsculo cae sobre los muros, recortados sobre los últimos vestigios del día, mientras se escucha, en voz del poeta: 
Eres de cielo hacia la tarde, tienes

Ya dorada la luz en las pupilas,

Como un poco de nieve atardeciendo

Que sabe que atardece.

Y yo querría

Cegar del corazón, cegar de verte

Cayendo hacia ti misma

Como la tarde cae, como la noche

Ciega la luz del bosque en que camina

De copa en copa cada vez más alta,

Hasta la rama isleña, sonreída

Por el último sol,

iY sé que avanzas

Porque avanza la noche! y que iluminas

Tres hojas solas en el bosque,

Y pienso

Que la sombra te hará clara y distinta,

Que todo el sol del mundo en ti descansa,

En ti, la retrasada, la encendida

Rama del corazón en la que aún tiembla

La luz sin sol donde se cumple el día. (Rosales 1982: 142)

Es el poema "La última luz". La versión manuscrita del mismo aparece luego, en escena. Y el espectador establece la conexión entre ambos, pero también evoca las imágenes poéticas de la tradición: el contraste entre luz y nieve (Villaespesa), los ciegos (Icaza, García Lorca), la luz sin sol y las sombras que se apoderan, progresivamente, de las ruinas (García Lorca). La metáfora elusiva deviene referencia.

\section{Conclusiones}

Hay múltiples procedimientos poéticos para hablar acerca de la ciudad; aquí, hemos escogido unos cuantos recursos, a propósito de Granada, como la descripción, la adjetivación, la estampa, la alusión y la elisión. Pero un objeto cultural multiforme admite una mayor cantidad de recursos y procedimientos. ¿Hasta dónde llegan los límites de ese inventario? Seguramente, su potencialidad es infinita: Cada creador hace suya la ciudad y nos la entrega a través de cada línea versal. Por ello, podemos concluir provisoriamente con las siguientes palabras de Rosalba Campra (1994: 20): "¿Quién es capaz de descubrir, entonces ese secreto discurrir de la ciudad? Sólo aquel que, además de recorrerlas, las haya leído...". 


\section{Bibliografía}

ALBERTI, Rafael (1972): Poesía (1924-1967). Madrid: Aguilar.

CAMPRA, Rosalba (1994): "La ciudad en el discurso literario". SYC, núm. 6, pp. 19-27.

CICERONE CULTURA Y OCIO, S.L. (s.a.): "Granada en la literatura" [en línea]. Cicerone Granada. En: http://www.ciceronegranada.com/espanol/web/granadaenlaliteratura. asp [Consulta: 30/08/2011].

EFE (2011): "Una nueva guía recorre la Alhambra de la mano de Luis Rosales" [en línea]. Hola24h, 21/06/2011. En: http://hola24h.hola.com/noticia/20110621640/una-nueva-guiarecorre-la-alhambra-de-la-mano-de-luis-rosales/ [Consulta: 01/10/2012].

GALLEGO MORELL, A. (1967): "El primer poema publicado por Federico García Lorca". Bulletin Hispanique, vol. 69, núm. 3-4, pp. 487-492.

HEFFES, Gisela (2008): Las ciudades imaginarias en la literatura latinoamericana. Rosario: Beatriz Viterbo.

HIDALGO, Ana Isabel (1993): "El arabismo en la obra de Federico García Lorca", en Eufemio Lorenzo Sanz (coord.), Proyección histórica de España en sus tres culturas, Castilla y León, América y el Mediterráneo. Actas del Congreso celebrado en Medina del Campo en 1991, vol. 2, pp. 405-408. León: Junta de Castilla y León, Consejería de Cultura y Turismo.

ICAZA, Francisco A. de (1980): Obras. México, D.F.: Fondo de Cultura Económica.

JIMÉNEZ, Juan Ramón (1994): Elejías andaluzas. Barcelona: Seix Barral.

MAURER, Christopher; y ANDERSON, Andrew A. (eds.) (1997): Epistolario completo / Federico García Lorca. Madrid: Cátedra.

PACHECO, José Emilio (2010): Discurso de aceptación del Premio Cervantes 2009 [en línea]. El País, 23/04/2010. En: http://www.elpais.com/elpaismedia/ultimahora/media/201004/23/cul tura/20100423elpepucul 1 Pes .pdf [Consulta: 12/12/2010].

REMEDI, Eduardo (2003): "Representaciones de la ciudad: Apuntes para una crítica cultural". Tram( $p$ )as de la Comunicación y la Cultura, vol. 2, núm. 18, pp. 38-52.

ROSALES, Luis (1982): Poesía reunida 1935-1974. Barcelona: Seix Barral. VILLAESPESA, Francisco (1917): Mis mejores versos. Madrid: Hesperia. - (1932): El encanto de la Alhambra. Madrid: José María Yagües editor.

WOJCIK, Sara (2010): "Andalucía en el Romancero Gitano de Federico García Lorca" [en línea]. En: http:/lateinamerika.phil-fak.uni-koeln.de http://lateinamerika.phil-fak.uni-koeln.de/fileadmin/sites/aspla/ bilder/ip 2010/trabajo Sara Wojcik.pdf [Consulta: 10/12/2010]. 